\title{
A Proposal of Concrete Structure Design Methods Considering Environmental Performance
}

\author{
Kenji Kawai ${ }^{1}$, Takafumi Sugimaya ${ }^{2}$, Koichi Kobayashi $^{3}$ and Susumu Sano ${ }^{4}$
}

Received 13 September 2004, accepted 13 January 2005

\begin{abstract}
This paper discusses concrete structure design considering the environmental impact generated in the manufacture, construction, service, maintenance, demolition, and disposal and recycling processes of the structure. Environmental impact, including its reduction, is considered as a performance parameter of the concrete structure, similarly to serviceability, safety, and durability. Two types of design methods that respectively verify environmental performance and consider environmental performance are proposed. The design method for verifying environmental performance is applicable when environmental performance is required of a concrete structure. In this type of design, verification of environmental performance is carried out in the planning stage and is followed by inspection in the planning stage as well as the operation stage. The design method for considering environmental performance is applicable whether or not environmental performance is required of a concrete structure. In this type of design, verification or selection of environmental performance is carried out in the planning stage, and inspection is performed in the operation stage. Regarding the verification method, two types of methods are proposed according to the diversity of environmental performance requirements.
\end{abstract}

\section{Introduction}

Considering the importance of sustainable development, environmental aspects should be taken into consideration in the design of concrete structures. Environmental consciousness has been widely emphasized in the manufacture, construction, maintenance, and demolition processes of concrete structures, as exemplified by the use of supplementary materials, the use of recycled aggregates, zero-emission activities in construction sites, and so on. However, the contribution of these actions to environmental impact reduction is not evaluated quantitatively.

The Committee on Concrete within the Japan Society of Civil Engineers (JSCE) organized the Sub-Committee on Effective Uses of Resources for Concrete in 1997 in order to develop and use concrete taking into account environmental considerations such as resource-saving and energy-saving. The development of a system for the effective use of resources and the preparation of an evaluation scale for the environmental impact of concrete structures were among the topics discussed by this sub-committee. As a result, an evaluation system of

\footnotetext{
${ }^{1}$ Associate Professor, Department of Social and Environmental Engineering, Hiroshima University, Japan.

E-mail: kkawai@hiroshima-u.ac.jp

${ }^{2}$ Associate Professor, Department of Civil Engineering, Gunma University, Japan.

${ }^{3}$ Lecturer, Department of Civil Engineering, Chubu University, Japan.

${ }^{4}$ Associate Research Scientist, Research \& Development Center, Taiheiyo Cement Corporation, Japan.
}

materials for the effective use of resources and an evaluation method for the environmental impact of concrete structures were put forth in a proposal (JSCE $1999 \mathrm{~b})$ that introduced the concept of eco-value as an evaluation index of concrete performance considering the life-cycle environmental impact. This index includes the performance requirements and eco-costs of concrete. The eco-cost equivalent to the life-cycle environmental impact of concrete is calculated through conversion of environmental impacts such as carbon dioxide and wastes emissions into cost (Tazawa et al. 1998). Because of time restrictions, however, discussions for concretizing these concepts did not occur. Although the importance of recycling is well understood, the effective use of resources has not become popular yet because recycling is relatively costly in many cases. Moreover, the environmental impact of the energy consumed through recycling must also be taken into account. Nevertheless, the consideration of environmental impact as a performance parameter of concrete and the quantification of environmental impact in terms of cost will make it possible to reduce the cost of concrete considering its environmental impact and to promote recycling that will contribute to a reduction in environmental impact.

Activities for the preparation for a concrete structure design method considering environmental aspects are being carried out not only in Japan but in many other countries as well ( $f i b$ 2004, etc.). These activities can be divided into two primary approaches, a conceptual approach and a numerical approach. In the conceptual approach, many kinds of countermeasures for environmental impact reduction are proposed, but in many cases there is no incentive to adopt these countermeasures. Glavind and Munch-Petersen (2002) proposed green concrete that uses many kinds of residual products from 
the concrete industry and other industries, such as fly ash, stone dust, concrete slurry, and sewage sludge incineration ash. The authors mentioned the compressive strength development and $\mathrm{CO} 2$ reduction of this type of concrete, but failed to indicate whether or not it is widely available to structures. A research cluster has been organized for the development of a consistent lifetime engineering technology of buildings and civil infrastructures (Sarja 2003), but it has not yet shown concrete measures for sustainable development. In the numerical approach, the development of an evaluation method of environmental impact using Life Cycle Assessment (LCA) has been carried out. Various LCA tools have been developed and released to the public, such as SimaPro, BEES, and GEMIS (fib 2004). However, these tools are usually prepared for the evaluation of a given object within a certain range. In Japan, the Architectural Institute of Japan (2003) has developed and published an LCA tool for buildings. The amounts of energy consumption, $\mathrm{CO}_{2}$ emission, $\mathrm{SO}_{\mathrm{X}}$ emission, and $\mathrm{NO}_{\mathrm{X}}$ emission over the life cycle of a building can be calculated with this tool, but since the environmental impact of a building over its service life is very large, the environmental impact associated with concrete is not focused on very much.

Although many approaches for considering environmental aspects in concrete structure designs are employed, a quantitative evaluation method for the contribution of the various strategies to environment impact reduction has not yet been prepared. In order to evaluate the environmental impact of concrete as one of the concrete performance parameters, similarly to the mechanical properties, serviceability, safety and durability of concrete, the preparation of an evaluation method for the environmental performance of concrete will be needed in the future.

In this study, methods of evaluating environmental impact associated with concrete structures are investigated. Two concepts of concrete design considering environmental impact are proposed. They consist of concrete structure design verifying environmental performance and concrete structure design considering environmental performance. The former type of design can be used when environmental performance is clearly required of a concrete structure. The latter type of design can be used whether or not environmental performance is clearly required of a concrete structure.

In assessing the environmental performance of concrete, many aspects associated with the term "environment" should be considered. This term subsumes not only energy consumption, carbon dioxide emissions, emissions of gaseous, liquid and solid polluting substances, and solid wastes, but also landscape and environmental aesthetics. However, it is not easy to take into account all these environmental factors in the environmental design of concrete. The best approach may be the use of a trial assessment method that includes selected environmental factors and is improved on a timely basis as new technologies are developed and applied.

When an assessment for environmental impact is carried out, the most difficult issue is how to express environmental factors. Since different units are employed to quantify different environmental factors, the magnitude of the factors cannot be directly compared, and some sort of conversion or weighting is needed. Weighting and the integration of environmental impact factors are also touched upon in this paper.

\section{Environmental performance}

In Japan, there are performance-based standard specifications for concrete structures regarding structural performance verification, seismic performance verification, construction and maintenance. In addition to these specifications, this paper proposes an evaluation method for the environmental impact of concrete whereby environmental impact is considered as a performance parameter of concrete. The relationship between this proposal and other specifications is shown in Fig. 1 (Kawai and Sugiyama 2002; 2003). Since the degree of environmental impact of a concrete structure is associated with every setup issue except its structure type, this proposal will be concerned with the whole design process of concrete structures.

This method is applicable in each stage of concrete construction and should be considered within the total life cycle of the concrete structure, as shown in Fig. 2. Although the total life cycle of a concrete structure should be considered when environmental design is performed, it is not easy to estimate the maintenance, demolition, disposal, and recycling stages of a concrete structure before its construction. In this case, environmental impact may be estimated in the manufacture and construction stages of the concrete structure.

\section{Concrete structure design verifying environmental performance}

\subsection{Design method concept}

This design method can be used when environmental performance is clearly required of a concrete structure. The environmental impact of concrete structures should be evaluated within the framework of Life Cycle Assessment (LCA), whereby the manufacture of materials, construction, maintenance, demolition, and disposal are comprehensively taken into account.

Figure 3 shows the verification and inspection flow of environmental design. Each stage throughout the life span of concrete structures comprises planning and verification in pair and operation with respective inspection. Subsequent inspections done during the manufacturing stage and each planning stage are to judge whether the respective verification is proposed in the proper manner, with verification and inspection being defined as follows (JSCE 1999a):

Verification - Judgment at the pre-execution stage as 


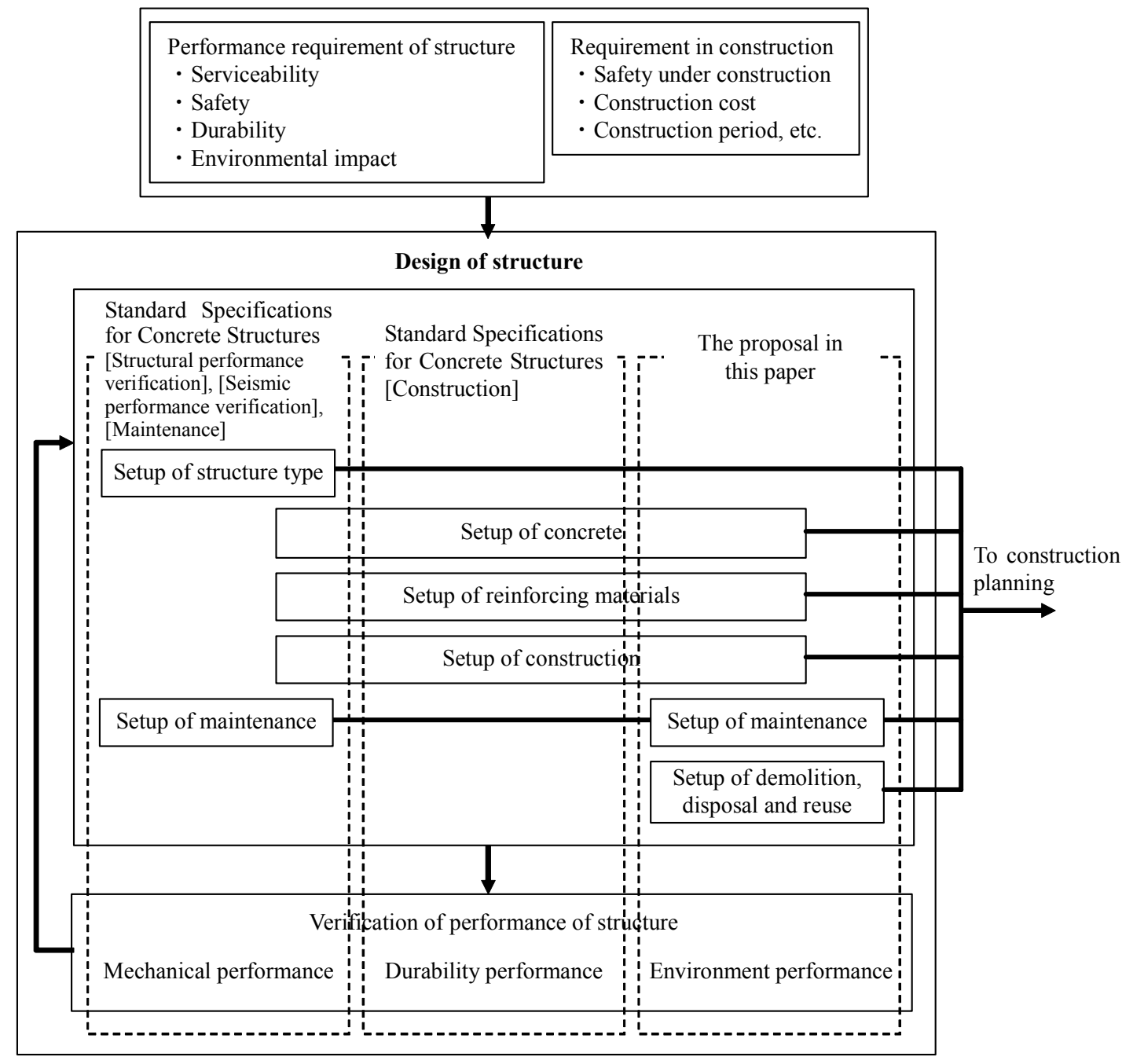

Fig. 1 Role of proposal in whole design of concrete structures.

to whether the designed and planned contents satisfy the performance requirements.

Inspection - Examination to judge whether the produced or placed concrete, members, or structures satisfy the performance requirements and are acceptable.

During the planning stage before the construction of a structure, the manufacture of materials plays an important role for the evaluation of environmental impact since a large amount of raw materials is consumed and used to make concrete at manufacturing plants. These materials also involve the need for transportation between service stations and plants. In addition, the environmental impact associated with construction periods can be relatively large depending on the nature of the construction site and its scale. The environmental impact of construction must be evaluated at the construction planning stage. The requirement of environmental assessment applied to the local region must also be separately met according to environmental laws.

The life-span of concrete structures is normally much longer than that of other products such as cars and elec- tronic equipment. There is also the fact that concrete structures are not mass-produced products. This makes it difficult to evaluate the environmental impacts of maintenance, demolition and disposal. The establishment of life cycle design for concrete structures facilitates the proper prediction of these impacts. Therefore, these environmental impacts may be evaluated during the maintenance planning stage and the demolition and disposal planning stage after construction.

\subsection{Factors related to environmental impact}

Quantitative values used to evaluate environmental impact are measured in terms of carbon dioxide emissions, energy consumption, resource saving and waste reduction, use of recycled materials, influence on surroundings, and influence on ecology and landscape. However, some factors are hardly quantified, which makes relative comparisons involving these factors difficult. The magnitude of these factors in terms of environmental impact is translated in an engineering sense and ranked by level (A, B, C..., etc.). In addition, each factor should be 


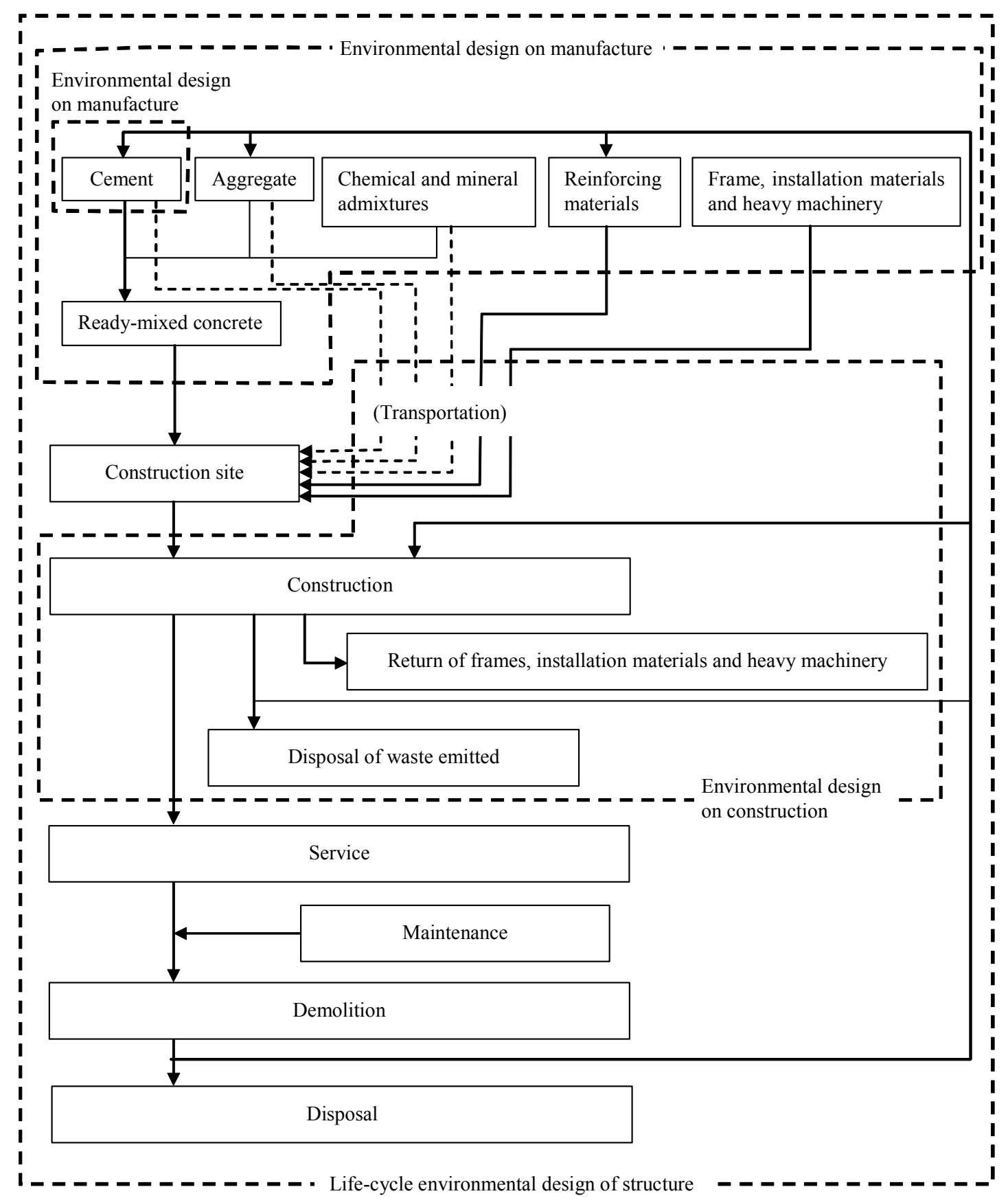

Fig. 2 Life cycle of concrete structure and environmental design.

properly weighted for respective degrees of environmental impact.

Table 1 lists some of the evaluation methods for concrete structures. The Life Cycle $\mathrm{CO}_{2}\left(\mathrm{LCCO}_{2}\right)$ method is applied to manufacture in general, although the use of recycled materials may be limited with this particular method since recycling processes consume energy resulting in an increase in $\mathrm{CO}_{2}$ emission compared with the use of virgin materials. Concrete is a material that can consume by-products and waste materials from other industries if properly treated. Therefore the use of recycled materials should not be limited for concrete struc- tures. In order to accomplish this, quantitative measurement of resource-saving and waste reduction needs to be included in parallel as a comprehensive evaluation method. The Eco-Value method is one of the comprehensive methods that consider environmental impact on a total basis (Tazawa et al. 1998). The key to applying this unique methodology to concrete structures is how to translate environmental factors into costs in comparison with real construction cost.

\subsection{Verification and inspection}

At each planning stage in environmental design, plans 

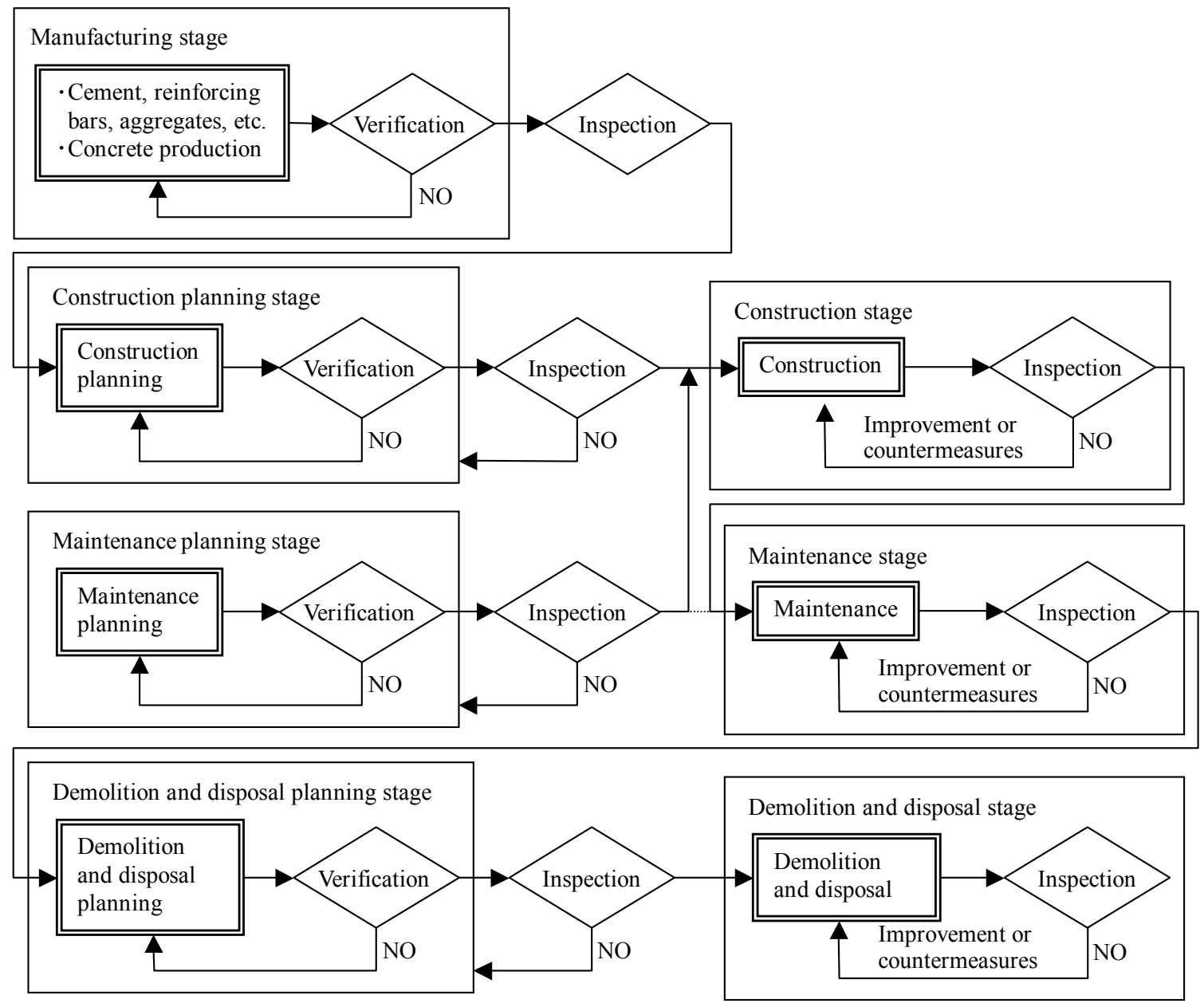

Fig. 3 Verification and inspection flow of environmental design.

Table 1 Environmental evaluation methods.

\begin{tabular}{|l|l|}
\hline \multicolumn{1}{|c|}{ Methodologies } & \multicolumn{1}{c|}{ Related factors } \\
\hline $\mathrm{LCCO}_{2}$ & Carbon dioxide emission \\
\hline Eco-Value & Performance requirement/(Construction Cost + Eco-Cost) \\
\hline Comprehensive manner & $\begin{array}{l}\text { Carbon dioxide emission, energy consumption, resource saving and waste reduction, use of } \\
\text { recycling materials, and so on }\end{array}$ \\
\hline
\end{tabular}

must be quantitatively verified and inspected for their correctness. Each action is also inspected in its operation stage using monitoring tools and written records to check whether or not it conforms to the planning. Proper countermeasures are to be taken promptly to improve the situation, if necessary.

Figure 4 shows an example of verification in environmental design during the construction planning stage. A standard or conventional construction method is compared with an alternative method with respect to environmental impact. The alternative method is designed to reduce environmental impact and will be employed if can successfully achieve the reduction requirement. An environmental performance requirement can be either absolute or relative, such as $5 \mathrm{t}$ of $\mathrm{CO}_{2}$ reduction or $5 \%$ of $\mathrm{CO}_{2}$ reduction relative to a conventional method. The reduction requirement may be pro- vided with an achieved percentage on given factors related to the goal of the environmental design.

\subsection{Discussions}

The advantage of this method is that the evaluation and inspection of the environmental performance of a concrete structure can be performed using the same methods as for other performance parameters such as serviceability, safety, and durability of the structure. However, there are number of issues, including the fact that during the selection of the materials and construction methods to be used for a structure, priority must be given to mechanical performance and durability since these performance parameters are strongly related to the construction cost of the structure, and the fact that such environmentally conscious approach will increase the construction cost. As already mentioned in Chapter 1, a system whereby 
environmental consciousness reduces the whole construction cost of a concrete structure must be established.

Regarding the verification of the environmental performance of a concrete structure, a qualitative statement may be used instead of the quantitative statement shown in Fig. 4. Also in that case, the preparation of a judgment criterion with several levels might be needed in order to verify the performance on a quasi-quantitative basis. If a quantitative statement is used, absolute requirements and relative requirements are available. In either case, multiple requirements can be stated. However, when providing multiple requirements, it is difficult to assign a priority to each of the requirements. That decision will depend upon the country and the district. In the case of Japan, the lack of waste treatment sites is a serious problem. Therefore, if the amount of waste emission is given as an environmental performance requirement, in many cases that requirement will have priority over other requirements. The application of an integration method to multiple requirements of environmental impact factors is one of the solutions. In this verification method, no weighting method is mentioned. When multiple environmental factors are considered as an environmental performance, the decision maker, designer, owner, or contractor of the structure should suggest a weighting method according to the construction conditions. Weighting factors will also change according to the country and district. Several of the factors used in an integration method will depend upon the country and district. A sample integration method in the verification is later described in Chapter 4. That verification method can be also applied to this design method.

\section{Concrete structure design considering environmental performance}

\subsection{Design method concept}

The fundamental concept of an evaluation method for the environmental impact of concrete has been described above. Usually the performance of a concrete structure is decided in terms of its serviceability, safety, and durability. If environmental performance is considered in addition, a number of solutions that satisfy the conventional performances will be obtained. After these solutions are compared, the best one has to be selected from the viewpoint of given aspects such as legal, political, or economical aspects. An example of this concept is shown schematically in Fig. 5. The difference between this method and the method mentioned in the previous chapter is the evaluation method employed in the planning stages. Instead of one method of verification, two selective methods of verification and selection are prepared. Moreover, no inspection is carried out after the planning stages in this method. Since verification or selection is carried out after considering the environmental aspects of a concrete structure, this method can be applied even though environmental performance is not clearly demanded of the structure.

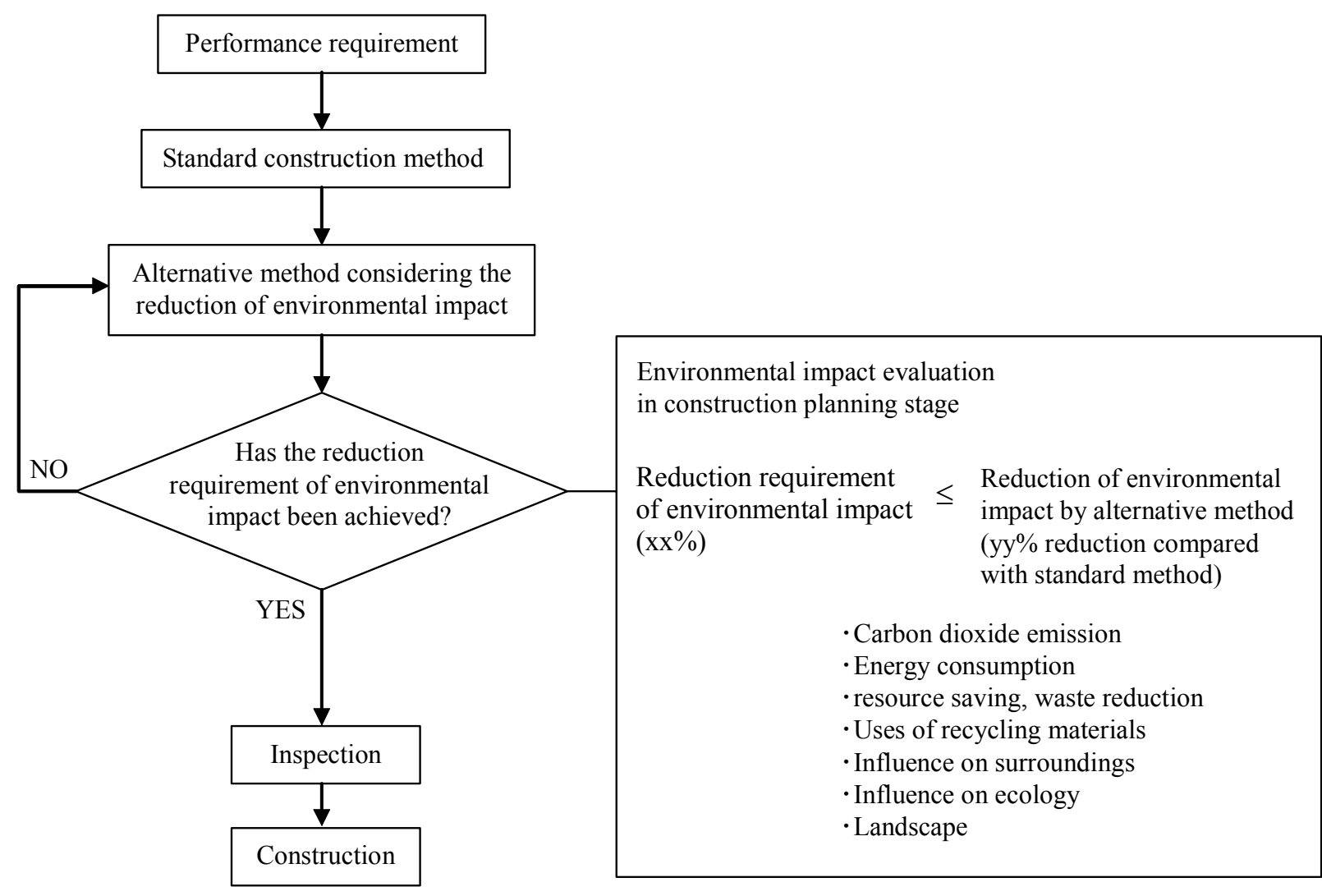

Fig. 4 Example of verification in environmental design (construction planning stage). 


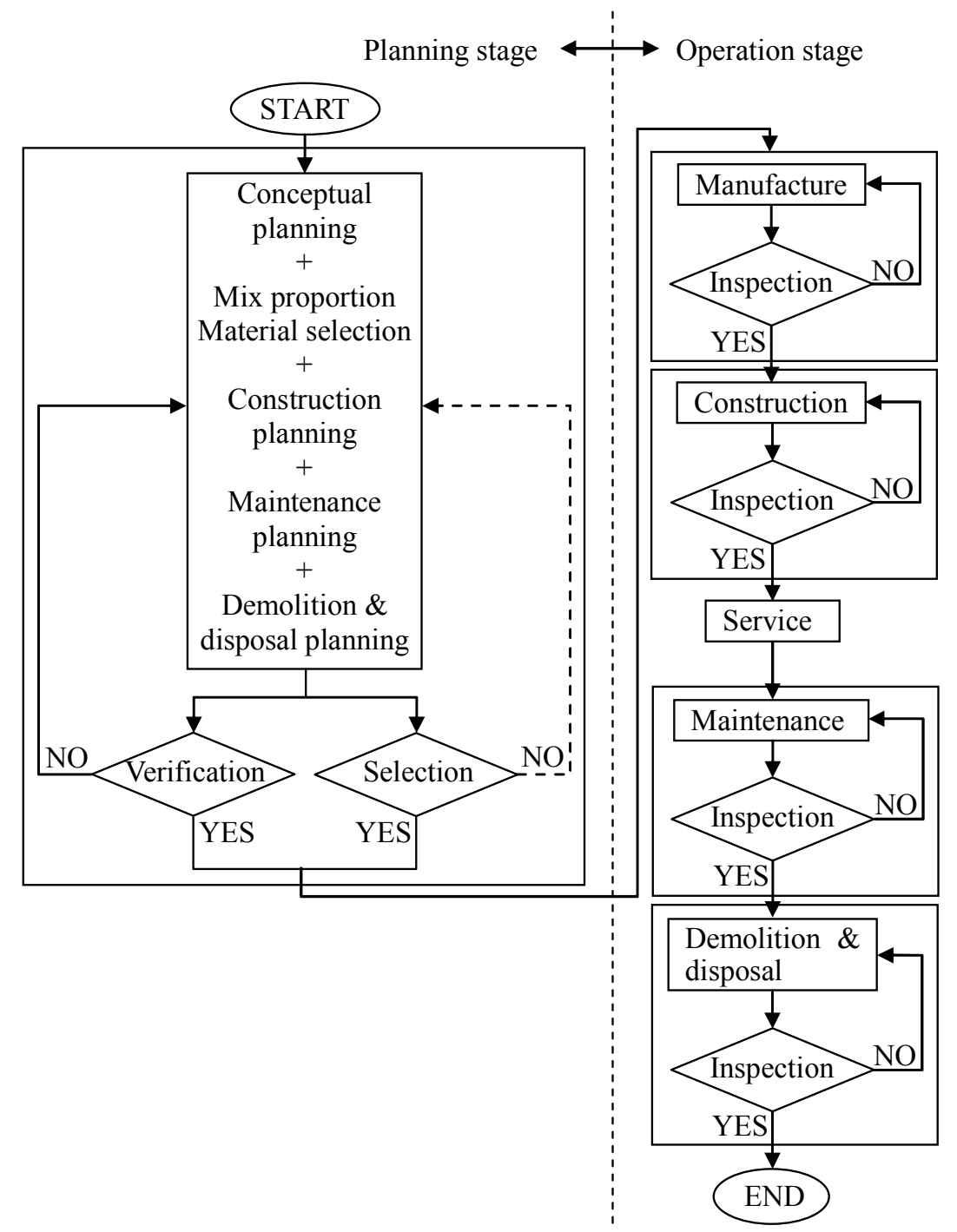

Fig. 5 Example of evaluation flow in environmental design of a concrete structure through its life cycle.

In this sense, the cost performance of a concrete structure is considered in this design. Although cost is also an important factor in design verifying environmental performance, the concept of cost is not included in the performances of a structure. In design considering environmental performance, cost is specifically included as a way to determine the performance of the structure. In other words, in the case of this design method, materials and construction methods will be selected so as to maximize cost performance in the process of selection. The difference between the verification and selection in design considering environmental performance is whether or not environmental aspects are clearly demanded as the performance of a structure.

\subsection{Verification, selection and inspection}

In the example shown in Fig. 5, the evaluations of all stages from manufacture to demolition and disposal are already carried out in the planning stage of the concrete structure. However, this is just an example of the flow, and each evaluation can also be carried out in each stage, if necessary. In the operation stages from manufacture to demolishment and disposal, whether or not the operation is carried out according to the planning is inspected. Regarding verification and selection, either action is performed. If quantitative environmental performance is specified in concrete structure construction, for example if a decision maker specifies that $\mathrm{CO}_{2}$ emissions throughout the construction of a concrete structure must be reduced by $5 \%$ compared to $\mathrm{CO} 2$ emissions using a conventional construction method, such verification is to be performed. If there is no specified environmental performance, selection will be done after considering the integrated environmental impact factors and the results of a cost survey for the construction of the concrete structure. 


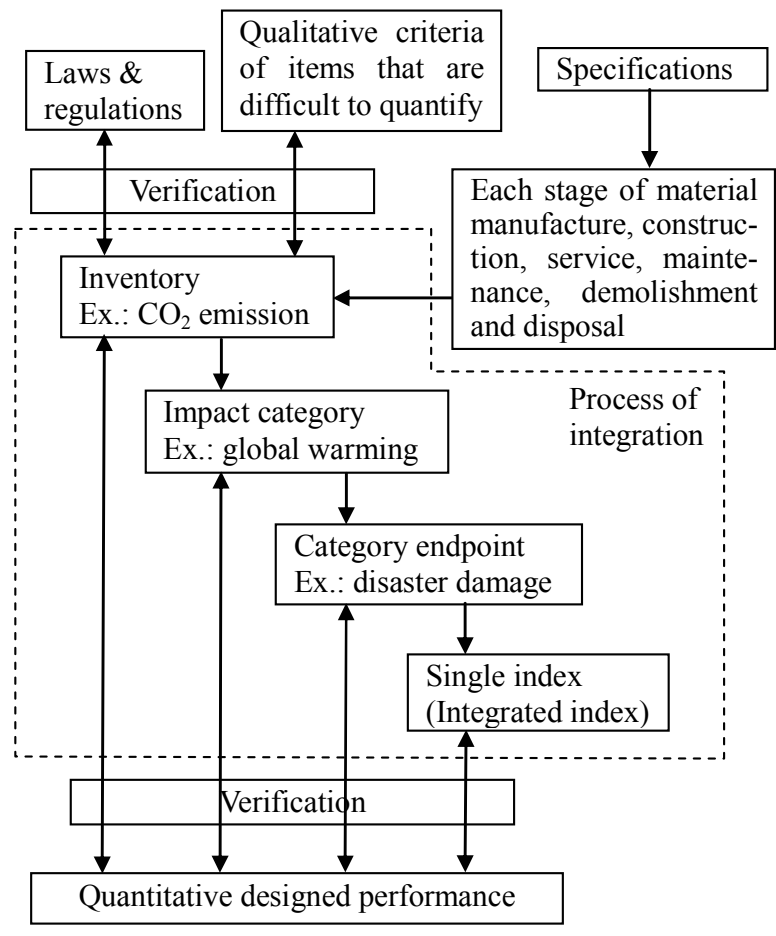

Fig. 6 Verification example.

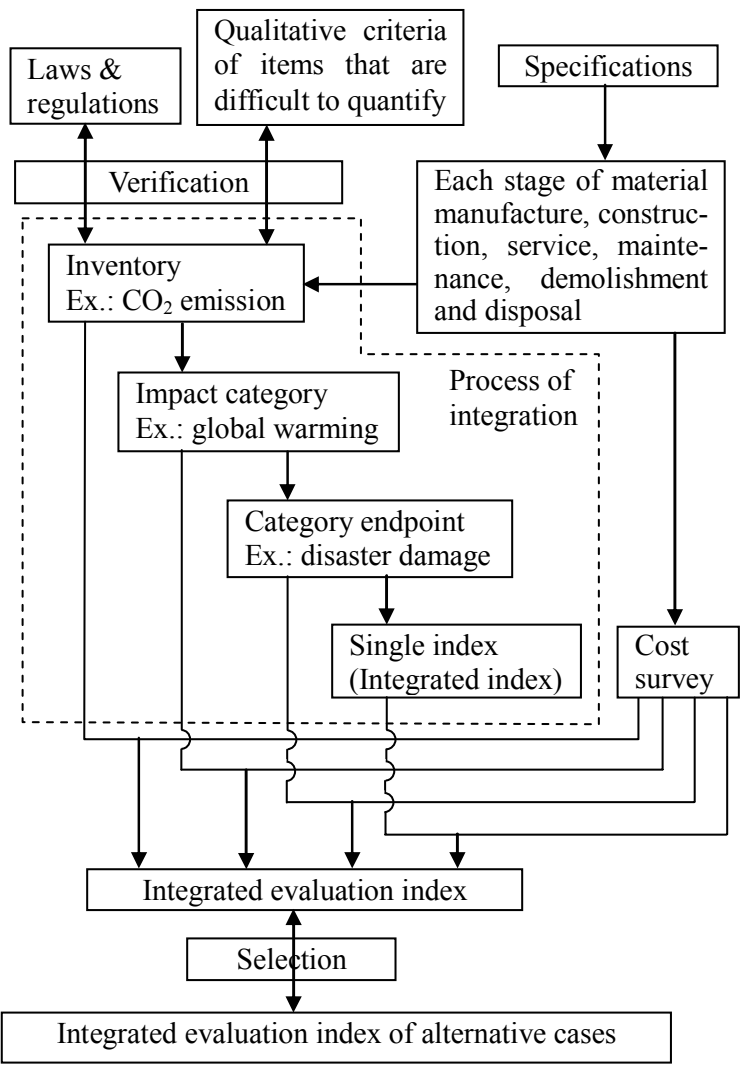

Fig. 7 Selection example.
Figure 6 and Fig. 7 each show an example of each case for these two actions. In these figures, as for the process of integration, this does not mean that all items of the inventory, the impact category, the category endpoint, and the single index, are verified or selected. Which item is picked up for verification or selection depends on the decision maker, designer, owner, and so on. When the environmental performance requirement for a concrete structure is specified as a certain value, the item appropriate to that specified value will be selected.

\subsection{Integration of each environmental impact factor}

When the environmental aspects of concrete structures are considered in concrete designs, multiple environmental factors that involve different units must be evaluated. Many kinds of integration methods have been proposed so far, and a comparison of these methods is shown in Table 2. The eco-indicator95 and eco-indicator99 methods were developed by Goedkoop at Pre Consultants, the Netherlands (Goedkoop 1996; 2000), the Environmental Priority Strategies for Production Design (EPS) system was originally developed by the Swedish Environmental Research Institute (IVL), the Federation of Swedish Industries, and Volvo Car Corporation, Sweden, the ecological scarcity (Ecopoint) method was developed by the Swiss Agency for the Environment, Forests and Landscape (BUWAL), the Swiss Federal Institute of Technology (ETH) Zurich, and
Migros Cooperative, Switzerland, the Environmental Load Point approach (ELP) was developed by Nagata at Waseda University, Japan (NEDO 1997), and the Life-cycle Impact Assessment Method based on Endpoint Modeling (LIME) was developed by the Research Center for Life Cycle Assessment, National Institute of Advanced Industrial Science and Technology, Japan (Yamaguchi 2003; JEMAI 2004). Each of these methods is a generalized method for the integration of environmental impact and is not designed to evaluate the environmental impact of concrete structures. Among these methods, the following conditions were needed to evaluate the environmental impact of concrete structures.

1) Possibility of evaluating the consumption of natural resources because of Japan's high dependency on imported natural resources

2) Possibility of evaluating waste emissions because of Japan's small land area

3) Possibility of considering limestone of a raw material of cement and aggregates in an evaluation

4) Inclusion of greatest possible number of environmental impact factors associated with the life cycle of reinforced concrete structures

Considering these conditions, natural resources cannot be evaluated with the ecological scarcity method, and waste emissions cannot be evaluated with the eco-indicator99 or EPS2000 methods. Limestone and aggregates are not considered in the ELP method. In this paper, therefore, the LIME method was adopted as the 
Table 2 Comparison of several integration methods.

\begin{tabular}{|c|c|c|c|c|c|c|c|}
\hline & & $\begin{array}{c}\text { Eco- } \\
\text { indicator95 }\end{array}$ & $\begin{array}{c}\text { Eco- } \\
\text { indicator99 }\end{array}$ & EPS2000 & $\begin{array}{c}\text { Ecological } \\
\text { scarcity } \\
\text { (Ecopoint) }\end{array}$ & ELP & LIME \\
\hline \multirow{11}{*}{$\begin{array}{l}\text { Primary } \\
\text { environmental } \\
\text { impact factors } \\
\text { that can be } \\
\text { evaluated }\end{array}$} & $\mathrm{CO}_{2}$ & $\mathrm{O}$ & $\mathrm{O}$ & $\mathrm{O}$ & $\mathrm{O}$ & $\mathrm{O}$ & $\mathrm{O}$ \\
\hline & SOx & $\mathrm{O}$ & $\mathrm{O}$ & $\mathrm{O}$ & $\mathrm{O}$ & $\mathrm{O}$ & $\mathrm{O}$ \\
\hline & NOx & $\mathrm{O}$ & $\mathrm{O}$ & $\mathrm{O}$ & $\mathrm{O}$ & $\mathrm{O}$ & $\mathrm{O}$ \\
\hline & Particle matters & $\mathrm{O}$ & $\mathrm{O}$ & $\mathrm{O}$ & $\mathrm{O}$ & $\mathrm{O}$ & $\mathrm{O}$ \\
\hline & Mineral resources & $\mathrm{X}$ & (Metals only) & $\mathrm{O}$ & $\mathrm{X}$ & (Metals only) & $\mathrm{O}$ \\
\hline & Fossil fuels & $\mathrm{X}$ & $\mathrm{O}$ & $\mathrm{O}$ & $\mathrm{O}$ & $\mathrm{O}$ & $\mathrm{O}$ \\
\hline & Waste & $X$ & $\mathrm{X}$ & $\mathrm{X}$ & $\mathrm{O}$ & $\mathrm{O}$ & $\mathrm{O}$ \\
\hline & Land & $\mathrm{X}$ & $\mathrm{O}$ & $\mathrm{O}$ & $\mathrm{X}$ & $\mathrm{X}$ & $\mathrm{O}$ \\
\hline & Water quality & $\mathrm{O}$ & $\mathrm{O}$ & $\mathrm{O}$ & $\mathrm{O}$ & $\mathrm{O}$ & $\mathrm{O}$ \\
\hline & Soil quality & $\mathrm{O}$ & $\mathrm{O}$ & $\mathrm{O}$ & $\mathrm{O}$ & $\mathrm{O}$ & $\mathrm{O}$ \\
\hline & Noise and vibration & $\mathrm{X}$ & $\mathrm{X}$ & (Vehicles only) & $\mathrm{X}$ & $\mathrm{X}$ & $\mathrm{X}$ \\
\hline \multicolumn{2}{|c|}{ Region } & Europe & Europe & Europe & Europe & Japan & Japan \\
\hline \multicolumn{2}{|c|}{ Weighting point } & Midpoint & Endpoint & Endpoint & Starting point & Midpoint & Endpoint \\
\hline \multicolumn{2}{|c|}{ Weighting method } & DtT & Panel & $\begin{array}{c}\text { Economical } \\
\text { evaluation }\end{array}$ & $\mathrm{DtT}$ & Panel & $\begin{array}{c}\text { Conjoint } \\
\text { analysis } \\
\text { AHP }\end{array}$ \\
\hline
\end{tabular}

O: possible, X: impossible, DtT: Distance-to-target approach, AHP: Analytic hierarchy process

method for integrating environmental impact. Furthermore, this method is suitable for Japan's industrial, economical and geographic conditions. The integration flow chart for LIME is shown in Fig. 8 (JEMAI 2004).

The LIME method sets forth four objects of protection consisting of human health, public assets, biodiversity, and primary production capacity, which have unique

indexes consisting of DALY (Disability-Adjusted Life Year, unit: year), YEN (Japanese monetary unit, unit: yen), EINES (Expected Increase Numbers of Extinct Species, unit: species) and NPP (Net Primary Productivity, unit: $\mathrm{t} / \mathrm{ha} / \mathrm{year}$ ), respectively. The degree of environmental impact can be evaluated with these four in- dexes and furthermore with a single index that is an integrated index of these four indexes.

The single index has three versions. The weighting factors for single indexes ver. 1 and ver. 2 have been obtained from the conjoint analysis that has been developed primarily in marketing research as a tool for measuring consumer preference. These weighting factors are based on the results of a questionnaire survey conducted on 400 persons whose age, sex, and income are various. Single index ver. 1 uses the yen unit and its weighting factor is an amount of marginal willingness to pay (MWTP) for each damage item, while single index ver. 2 has no dimension and its weighting factor is a ratio

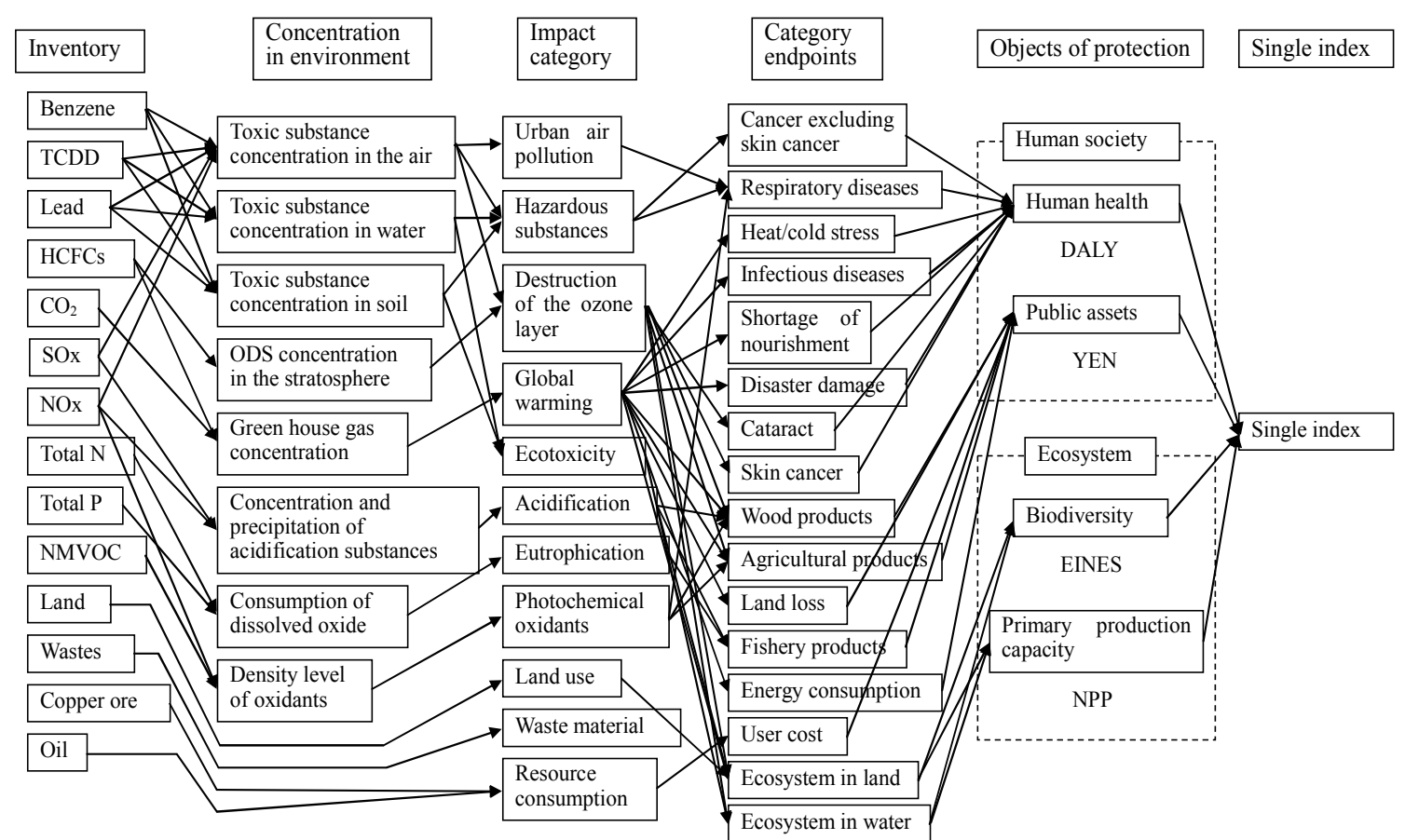

Fig. 8 Outline of Life Cycle Impact Assessment method based on Endpoint Modeling (LIME). 
of each annual damage amount calculated from the product of the amount of MWTP for each damage item and its annual magnitude. The weighting factors for single index ver. 3 are obtained from the AHP (Analytic Hierarchy Process) method that is a multi-criteria decision-making approach and indicates decisions by weighing the evaluation criteria and making pair-wise judgments of a set of alternatives. Single index ver. 3 has no dimension and its weighting factor is also based on the results of the above-mentioned questionnaire survey. LIME recommends the use of single index ver. 1 or ver. 2 whose weighting factor is derived from economics theory, but single index ver. 3 can be used for sensitivity analysis in life cycle interpretation. Since the significance of the utilization of this index is to enable comparison between the degrees of environmental impact for a conventional method and an alternative method, either version of the index can be used in this evaluation method and it is thought that the magnitude of the index itself is not too important here.

\subsection{Discussions}

In the verification of the mechanical properties and durability of a concrete structure, the structure must satisfy the performance requirements described as values. But in the case of the environmental performance, there is a possibility that the performance requirement of a concrete structure is stated qualitatively since the determination of environmental performance may be difficult. In that case, a factor other than environmental performance has to be considered together with environmental impact. That factor which will be important in a concrete structure design should be a cost. As for environmental impact, some integrated values can be obtained. Both the integrated environmental impact factors and the cost of a concrete structure become a ground of evaluation. The performance of this evaluation is defined here as selection. Therefore in this method, the environmental impact of a concrete structure can be considered regardless of a quantitative or qualitative description of environmental performance.

Regarding the selection of the integration method for environmental impact, the LIME method is considered to be the best method for Japan at present, but not for other countries. Since economical, industrial, and social conditions significantly differ in each country, the integration method should be adopted according to the circumstances of each country. Even though either integration method is selected, the evaluation method proposed in this paper can be used, although the items evaluated in the verification or selection may differ for each integration method.

As environmental impact factors integrated in the LIME method, the inventory data of material recycling, waste emission, $\mathrm{CO} 2$ emission, $\mathrm{SO}_{\mathrm{X}}$ emission, $\mathrm{NO}_{\mathrm{X}}$ emission, and dust emission regarding materials, machines, and treatment methods associated with the life cycle of reinforced concrete structures have been inves- tigated and prepared by the authors. Using these data, environmental performance evaluation is feasible for any concrete structure design.

\section{Conclusions}

This study has developed and proposed concepts of a concrete structure design considering environmental aspects of manufacture, construction, service, maintenance, demolition, and disposal and recycling. These concepts include two methods consisting of design that verifies environmental performance and design that considers environmental performance. The former design method is available when environmental performance is clearly required of a concrete structure, while the latter design method can be used whether or not environmental performance is clearly required of a concrete structure. In either method, environmental performance can be evaluated both quantitatively and qualitatively, and multiple environmental performance requirements can be integrated for evaluation if a set of inventory data related to environmental impact is prepared. By using these design methods, the environmental impact associated with a concrete structure can be explicitly evaluated as a performance of the structure along with other performances.

\section{Acknowledgements}

This study was carried out by the Sub-Committee on Assessment for Environmental Impact of Concrete, Committee on Concrete, Japan Society of Civil Engineers, Japan. The authors would like to express their gratitude to all the members of this sub-committee for their valuable contributions. This study was supported in part by Grant-in-Aid for Scientific Research No. 14350234 from the Japan Society for the Promotion of Science (JSPS), Japan, by Grant-in-Aid for Scientific Research from the Kajima Foundation, Japan, and by Grant-in-Aid for Special Research from the Electric Technology Research Foundation of Chugoku, Japan.

\section{References}

AIJ (2003). "Recommendations for LCA of Buildings Towards Application to Design for Environment, Environmental Labeling and Environmental Accounting." Tokyo: Architectural Institute of Japan. (in Japanese)

BUWAL (1997). "Bewertung in Okobilanzen mit der Methode der okologischen Knappheit." Schriftenreihe Umwelt Nr. 297.

fib (2004). "Environmental Design." Stuttgart: Sprint-Digital-Druck. fib bulletin 28.

Glavind, M. and Munch-Peterson, C. (2002). "Green concrete - a life cycle approach.” In: R. K. Dhir, T. D. Dyer and J. E. Halliday, Eds. The International Conference on Challenges of Concrete Construction, Dundee 9-11 September 2002. London: Thomas Telford Publishing. Sustainable Concrete 
Construction, 771-786.

Goedkoop, M., Demmers, M. and Collignon, M. (1996). "The Eco-indicator95 Manual for Designers." Pre Consultants.

Goedkoop, M. and Spriensma, R. (2000). "The Eco-indicator99, a Damage Oriented Method for Life Cycle Impact Assessment, Methodology Report." 2nd Edition.

JEMAI (2004). "Report on Development of Assessment Technology of Life Cycle Environmental Impacts of Products and So Forth." Tokyo: Japan Environmental Management Association for Industry. (in Japanese)

JSCE (1999a). "Recommendation for Self-Compacting Concrete." Tokyo: Japan Society of Civil Engineers. Concrete Engineering Series 31.

JSCE (1999b). "State-of-the-Art Report on Effective Uses of Resources." Tokyo: Japan Society of Civil Engineers. Concrete Library 96. (in Japanese)

JSCE (2002). “Assessment for Environmental Impact of Concrete." Tokyo: Japan Society of Civil Engineers, Concrete Engineering Series 44. (in Japanese)

JSCE (2004). “Assessment for Environmental Impact of Concrete (Part 2)." Tokyo: Japan Society of Civil Engineers. Concrete Engineering Series 62. (in Japanese)

Kawai, K. and Tazawa, E. (2000). "An assessment method for environmental impact of concrete." In: A. Sarja Ed. RILEM/CIB/ISO International Symposium on Integrated Life-Cycle Design of Materials and Structures, Helsinki 22-24 May 2000. 334-339.

Kawai, K. and Sugiyama, T. (2002). "Concrete design considering environmental performance." In: R. K. Dhir, T. D. Dyer and J. E. Halliday, Eds. The
International Conference on Challenges of Concrete Construction, Dundee 9-11 September 2002. London: Thomas Telford Publishing. Sustainable Concrete Construction, 457-464.

Kawai, K. and Sugiyama, T. (2003). "Life cycle design concept considering environmental performance." In: 2nd International Symposium on Integrated Lifetime Engineering of Building and Civil Infrastructures, Kuopio 1-3 December 2003. 73-78.

NEDO (1997). “A study of Impact Assessment for Life Cycle Assessment." New Energy and Industrial Technology Development Organization. Research report 9632. (in Japanese)

Sarja, A. (2003). "A process towards lifetime engineering in the 5th and 6th framework program of EU." In: 2nd International Symposium on Integrated Lifetime Engineering of Building and Civil Infrastructures, Kuopio 1-3 December 2003. 7-12.

Steen, B. (1999). "A Systematic Approach to Environmental Property Strategies in Product Development (EPS). Version 2000 - Models and Data of the Default Method," CPM report.

Tazawa, E., Kawai, K. and Kawasaki, W. (1998). "The application of the concept of eco-value engineering to environmental impact assessment." Concrete Engineering Series 29: Effective Uses of Concrete and Resources, Part II Symposium Proceedings, II-157-II-162. (in Japanese)

Yamaguchi, S. (2003). "Efforts for the Diffusion of Performance-based Evaluation Contract Method with a Technical Proposal." 2003 Annual Report of NILIM (National Institute for Land and Infrastructure Management), 103. 